\title{
Glucose Tolerance in Two Unacculturated Indian Tribes of Brazil
}

\author{
R.S.Spielman', S.S.Fajans ${ }^{2}$, J.V. Neel ${ }^{3}$, S.Pek ${ }^{2}$, J.C.Floyd ${ }^{2}$ and W.J.Oliver ${ }^{4}$ \\ 'Department of Human Genetics, University of Pennsylvania School of Medicine, Philadelphia, and Departments of ${ }^{2}$ Internal Medicine, \\ ${ }^{3}$ Human Genetics, and ${ }^{4}$ Pediatrics, University of Michigan Medical School, Ann Arbor, USA
}

\begin{abstract}
Summary. Plasma levels of glucose, insulin, growth hormone, and pancreatic polypeptide in response to a standard oral glucose load were studied in the Yanomama and the Marubo, two relatively unacculturated Amerindian tribes of the Brazilian Amazon. The findings in the two tribes differed significantly from each other and in the degree of deviation from control subjects. The average responses in both tribes differed significantly from those of age- and sex-matched Caucasoid control subjects studied in Ann Arbor, Michigan; however, of the two tribes, the Marubo, the more acculturated group, resembled the controls more closely. Plasma concentrations of glucose and the hormones at three time points (fasting, $1 \mathrm{~h}$, $2 \mathrm{~h}$ ) were compared by means of a multivariate analysis. When the Marubo were compared with the control subjects,
\end{abstract}

the only highly significant difference was in the plasma glucose concentrations (all three points were higher in the Marubo); however, the Yanomama differed significantly from the control subjects with respect to all four plasma indicators $(p<0.05)$. Unlike the Marubo, the Yanomama showed no significant rise in plasma glucose at $1 \mathrm{~h}$ and no decrease at $2 \mathrm{~h}$. Neither tribe exhibited the bimodality of the $2 \mathrm{~h}$ glucose value characteristic of acculturated Amerindians, such as the Pima, but the samples studied were small.

Key words: Oral glucose tolerance, plasma insulin, growth hormone, pancreatic polypeptide, Amerindian tribes, Marubo, Yanomama.
It has been suspected for some time that diabetes mellitus, particularly the non-insulin-dependent type, is a 'disease of civilization.' One particularly suggestive line of evidence comes from the extraordinarily high prevalence of glucose intolerance and overt diabetes in certain highly acculturated American Indian tribes [1-9] as well as among other recently primitive peoples [10-13]. It has been generally assumed that diabetes mellitus was relatively uncommon in these groups before their contacts with Western civilization, and has emerged in consequence of the recent change in their way of life which resulted from these contacts.

Baseline data on glucose metabolism and tolerance among reasonably undisturbed, pre-civilized peoples remain extremely rare. To our knowledge, the only studies of this kind were carried out by Rimoin, Merimee and associates on African Babinga pygmies and Bantu tribesmen $[14,15]$. These studies suggest that the pygmies are distinctive in their response to a glucose load, particularly in their apparently normal handling of glucose with a minimal mobilization of insulin. While it is possible that this response is a general characteristic of primitive man, it is more likely that the pyg- mies do in fact exhibit lower insulin responses to glucose since they are deficient in growth hormone activity and have increased peripheral sensitivity to insulin.

In the course of fieldwork in 1976 among the Amerindian tribes of the Amazon basin we had the opportunity, under rather difficult field conditions, to augment the few existing observations on glucose tolerance in pre-civilized peoples with data on two tribes, the Marubo, who belong to the Central Pano, and the Yanomama. Although the numbers of subjects studied are modest, our studies provide the only data available for such peoples from the western hemisphere. The interpretation of the findings is complicated by an unexpected difference between the results in the two tribes.

\section{Methods}

\section{Subjects}

The study was restricted to healthy active young males with estimated ages between 18 and 35 years. The Marubo $(n=11)$, studied at the New Tribes Mission of Vida Nova at about $6^{\circ} 47^{\prime} \mathrm{S}$ latitude, $72^{\circ} 08^{\prime} \mathrm{W}$ longitude, are a subdivision of the Central Pano, whose present status 
was briefly summarized by Mohrenweiser et al. [16]. Although most of this group are now relatively acculturated, the Marubo have remained isolated until the last 30 years. However, with the effort to extend the Brazilian perimeter highway into this region, both government and mission groups have been more active in this area. In 1960 the New Tribes Mission initiated permanent contacts with the group. This usually consists of two couples living at a small outpost near a Marubo village. The Indian villages studied are near the Paraguaçu River. An occasional group of young Indians descends the river to the Amazon port town of Benjamin Constant, making contact with lumber workers as they go, and from time to time a neo-Brazilian trader ascends the river in search of skins. The Mission personnel have introduced salt as an item of barter for services, but have otherwise disturbed the dietary patterns of the Indians very little. Salt intake undoubtedly remains very low by the standards of civilization.

The Yanomama $(n=17)$ were studied at the New Tribes Mission of Mararí, just south of the Venezuelan border, at about $1^{\circ} 17^{\prime} \mathrm{N}$, $64^{\circ} 50^{\prime} \mathrm{W}$. The general lack of acculturation of the Yanomama has been described previously [17-19]. Access other than by small plane to this station (established in 1969) is extremely arduous; the Indians' only contact with non-Yanomama other than the few missionaries consists of infrequent visits by Brazilian public health groups and research groups. The missionaries do not distribute salt and the Indians maintain their native diet with the cooking banana ( $M u$ usa spp.) as the staple; meat is eaten when available. The normal diet is therefore high in carbohydrate. This is probably true of the Marubo as well. Refined carbohydrates are not available to the Indians at either Mission.

The control subjects were 28 healthy male Caucasoid volunteers from Ann Arbor chosen to give an age distribution approximating that of the Indian subjects. All controls gave informed consent. Additional control glucose tolerance tests were performed at the same time as the Indian studies on three members of the field team. The small size of this latter sample precludes statistical analysis, but the results do provide a check on field processing and storage of specimens. One member of the field team had a glucose tolerance test at both Indian stations; the results of the two tests were very similar.

\section{Glucose Tolerance}

The Indian subjects were recruited the day before the glucose tolerance test was performed. The missionaries, who served as interpreters, obtained informed consent and stressed the importance of an overnight fast preceding the test. A fasting blood specimen was obtained before $07.00 \mathrm{~h}$ from every subject. Between 07.00 and $08.00 \mathrm{~h}$ a glucose load in the form of 'lemon sour' (VWR Scientific Co., Columbus, Ohio) was ingested. The dose for the Marubo was $1.75 \mathrm{~g} / \mathrm{kg}$ actual body weight; for the control subjects $1.75 \mathrm{~g} / \mathrm{kg}$ ideal body weight; a uniform dose of $100 \mathrm{~g}$ was given to the Yanomama. For the Yanomama, whose weight varied from 48.1 to $60.3 \mathrm{~kg}$, this corresponded to a range in dose of 1.7 to $2.1 \mathrm{~g} / \mathrm{kg}$ (mean $\pm \mathrm{SD}: 1.8 \pm 0.12$ ). Obesity is rare in the Marubo and the Yanomama, and none of the Indians studied was overweight; all appeared in good nutritional balance. Actual weight was thus close to ideal body weight, at least as defined for predominantly Caucasoid North American populations and consequently the glucose challenge did not differ greatly between the three groups. Additional blood specimens were taken 1 and $2 \mathrm{~h}$ after the glucose meal; all samples were drawn in heparinized tubes and placed on ice immediately. Red cells were spun down with a hand centrifuge within $2 \mathrm{~h}$, and the plasma was kept in an ice bath without preservative until it was transported by air to the base ship, where it was frozen $24-30 \mathrm{~h}$ later. The plasma specimens remained frozen at $-20^{\circ} \mathrm{C}$ until the assays were performed approximately 1 year later. The two sets of samples were handled identically in the field and were assayed together in the same batch in Ann Arbor.

\section{Laboratory Procedures}

For each subject, the three plasma samples were analyzed for glucose, immunoreactive insulin, pancreatic polypeptide, and growth hor- mone. Plasma glucose was determined by the hexokinase method of Bondar and Mead [20] and plasma insulin by the method of Morgan and Lazarow [21]. Plasma levels of human pancreatic polypeptide were assayed by a double-antibody radioimmunoassay method [22]; the assay procedure for human growth hormone was essentially that of Berger et al. [23]. The sensitivity and intra-assay coefficients of variation of these assays were: plasma glucose: $0.3 \mathrm{mmol} / 1,1.2 \%$; insulin : $0.15 \mu \mathrm{U} /$ tube, $8.1 \%$; pancreatic polypeptide: $2.4 \mathrm{pg} /$ tube, $10.1 \%$; growth hormone: $20 \mathrm{pg} /$ tube, $7.8 \%$.

\section{Statistical Analysis}

The results were analyzed by multivariate methods [24]. Since each type of plasma determination is treated as a separate variable, an individual is characterized by an array of observations or variables, a group by an array of means. The variances and correlations among variables are explicitly taken into account and the differences between two such arrays are condensed into a single number (Mahalanobis' $D^{2}$ or Hotelling's $T^{2}$ ) which serves as a composite measure of differences between group means. A particular advantage of combining information from many variables is that it obviates the evaluation of many separate but correlated comparisons, a procedure which artificially inflates the apparent significance of the differences.

\section{Results}

The results for the four plasma components for Indian and control subjects are shown in Table 1. The control values are typical of those encountered in other studies from this laboratory, except for the failure to observe a decline in growth hormone after the administration of glucose. Close examination of Table 1 suggests that, except perhaps for plasma glucose, the data from the Yanomama all deviated further from the control subjects than did those from the Marubo. For plasma glucose, the Yanomama response was 'flat' compared with the control subjects, while the Marubo response, though similar in shape, was shifted upward. Both Indian glucose tolerance tests, therefore, appear 'deviant' but in different ways.

Even single sets of three points are difficult to compare objectively by univariate methods. When there are four such sets, as in the present data, it is essential to use a multivariate method. When this was done, the analysis confirmed the impression that the Yanomama response differed from that of the Marubo. If the Yanomama were compared directly with the Marubo, the aggregate $\mathrm{D}^{2}$ for 12 variables was $13.9(p<0.005)$. The largest contribution to this difference was made by pancreatic polypeptide, and $\mathrm{D}^{2}$ was not quite significant $(p \approx 0.06)$ if this component was ignored. The analysis also confirmed that the Yanomama deviated more from the control subjects than did the Marubo. The $\mathrm{D}^{2}$ for the Yanomama-control comparison was $17.0(p<$ $0.001)$; that for the Marubo-control only $4.6(p=0.05)$. Although the levels of pancreatic polypeptide accounted for a large part of this difference, there was also evidence from the other variables that the Yanomama were more different from the control subjects than were the Marubo. When $\mathrm{D}^{2}$ was calculated separately for 
Table 1. Concentration of glucose and relevant hormones in the plasma of two tribes of South American Indians and Caucasoid control subjects during a $2 \mathrm{~h}$ oral glucose tolerance test

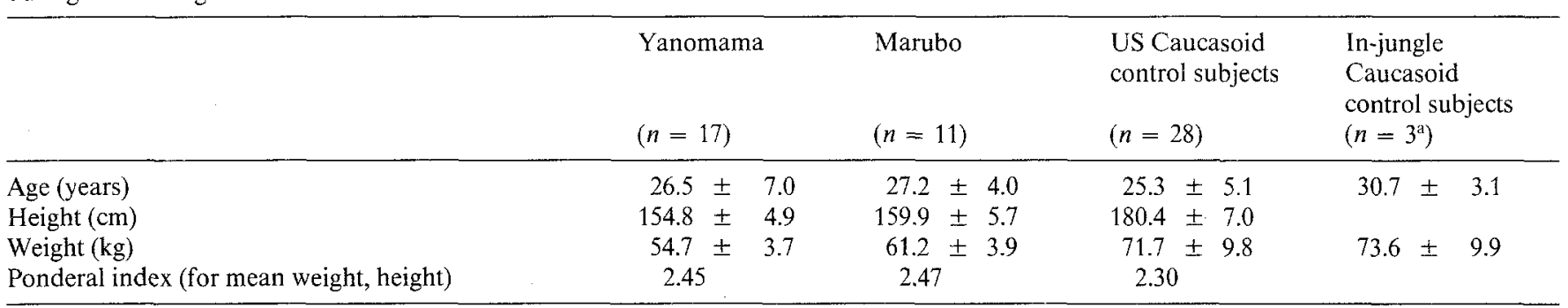

\begin{tabular}{|c|c|c|c|c|c|}
\hline & $\begin{array}{l}\text { Time } \\
(\min )\end{array}$ & & & & \\
\hline Plasma glucose $(\mathrm{mmol} / \mathrm{l})$ & $\begin{array}{r}0 \\
60 \\
120\end{array}$ & $\begin{array}{l}4.9 \pm 0.8 \\
5.0 \pm 1.0 \\
5.2 \pm 1.5\end{array}$ & $\begin{array}{l}5.2 \pm 0.6 \\
6.6 \pm 2.1 \\
5.9 \pm 1.4\end{array}$ & $\begin{array}{l}4.7 \pm 0.5 \\
5.8 \pm 1.2 \\
4.5 \pm 1.0\end{array}$ & $\begin{array}{l}5.2 \pm 0.7 \\
5.4 \pm 0.1 \\
4.7 \pm 1.1\end{array}$ \\
\hline Plasma insulin (mU/l) & $\begin{array}{r}0 \\
60 \\
120\end{array}$ & $\begin{array}{l}10.5 \pm 5.1 \\
52.5 \pm 34.9 \\
42.9 \pm 32.0\end{array}$ & $\begin{array}{r}9.7 \pm 3.6 \\
87.2 \pm 65.2 \\
56.3 \pm 32.5\end{array}$ & $\begin{array}{l}10.4 \pm 4.5 \\
95.0 \pm 47.2 \\
57.2 \pm 21.9\end{array}$ & $\begin{array}{r}5.5 \pm 3.9 \\
40.0 \pm 24.6 \\
35.5 \pm 32.5\end{array}$ \\
\hline Plasma human growth hormone $(\mu \mathrm{g} / \mathrm{l})$ & $\begin{array}{r}0 \\
60 \\
120\end{array}$ & $\begin{array}{ll}1.11 \pm & 0.71 \\
0.96 \pm & 0.18 \\
0.98 \pm & 0.24\end{array}$ & $\begin{array}{l}2.26 \pm 2.41 \\
1.48 \pm 1.11 \\
1.80 \pm 1.50\end{array}$ & $\begin{array}{l}3.13 \pm 1.53 \\
3.47 \pm 1.82 \\
3.20 \pm 1.57\end{array}$ & 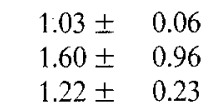 \\
\hline
\end{tabular}

Results are expressed as mean \pm SD. Time ' 0 ' sample was obtained after an overnight fast. a Three members of the fieldwork team served as control subjects, but one individual was given a glucose tolerance test on both occasions that Indians were studied. The two resulting values for each plasma determination were averaged

each set of three determinations, all four sets were significant for the Yanomama $(p<0.05)$, and the glucose and pancreatic polypeptide arrays were highly significant $(p<0.01)$. For the Marubo, the deviation of the glucose array was highly significant $(p<0.01)$, that of growth hormone barely significant $(p=0.05)$ and neither of the other components deviated significantly from the control subjects.

\section{Discussion}

The present studies were motivated by two previous sets of findings: the unusually high prevalence of overt diabetes and glucose intolerance in various tribes of North American Indians and studies on the Bantu and the much less acculturated pygmies $[14,15]$. All but the latter group had undergone considerable acculturation before being studied. Thus it seemed possible that the very unusual insulin response of the pygmies to a glucose load was characteristic of undisturbed primitive man. This possibility receives no support from the present study. Both the Yanomama and Marubo are much less acculturated than any US Indian tribe, but neither exhibits the flat insulin response of the pygmies. In this connection, we note that the Yanomama are quite small in stature, in some portions of their distribution almost pygmoid [25] and that growth hormone levels in both tribes appear to be lower after an oral glucose load than those of the control subjects.
The finding that the two tribes differ significantly from each other is unexpected. With respect to plasma glucose alone, the slightly more acculturated Marubo are clearly the more deviant (Table 1). The limited data available suggest that the Marubo deviate in the same direction as do the more highly acculturated Amerindians, for example, the Pima Indians, for whom data on glucose tolerance are available [26]. Comparison with our results is complicated by the bimodality of the Pima data, and by the facts that their glucose tolerance tests were not preceded by a fast and that the glucose dose was only $75 \mathrm{~g}$. However, we have calculated from the data [26] that at the mean age of our two South American samples (26.5 years), the Pima Indians would have a $2 \mathrm{~h}$ glucose level of approximately $7.8 \pm 5.6 \mathrm{mmol} / 1$. We conclude that the Marubo $2 \mathrm{~h}$ level $(5.9 \mathrm{mmol} / \mathrm{l})$, though significantly higher than for control subjects, is much less elevated than the corresponding value for the Pima. Thus, neither South American tribe shows the dramatic glucose intolerance of the highly acculturated (and quite obese) North American Pima.

With respect to the differences among the three groups studied, one possible explanation is different distributions of weight. Direct measurements of adiposity (by skin-fold thickness) are not available, but a roughly comparable measure is provided by the ponderal index: $100 \mathrm{x}$ weight ${ }^{1 / 3} /$ height. Calculated for the mean height $(\mathrm{cm})$ and weight $(\mathrm{kg})$ of our subjects, the ponderal index is 2.45, 2.47, and 2.30 for the Yanomama, Marubo, and Caucasoid control subjects, respec- 
tively. The standard deviation within a group is $0.6-0.8$, so the very similar values of the index for the two Indian tribes imply that the weight difference between them is almost exactly accounted for by differences in height (the Marubo average $5.0 \mathrm{~cm}$ taller). The smaller ponderal index for the Caucasoid control subjects (on average $20.6 \mathrm{~cm}$ taller still) indicates that they are less heavy for their height than the Indians. We recognize that the ponderal index is only a crude measure of adiposity, especially when applied across ethnic groups in this manner. Nevertheless, there is certainly no evidence that the Yanomama's total response to the glucose challenge is due to a lesser degree of adiposity.

Can the statistically significant differences between our three groups be due to artefacts, rather than reflecting genuine metabolic differences? The in-jungle control glucose tolerance tests suggest that no significant deterioration occurred during storage or transport of the samples. Thus technical artefacts seem unlikely. In contrast to the Ann Arbor control subjects, the Indians were all highly heat adapted and on low salt diets [27], but no reason for relating the difference between the two tribes to the probably small difference in salt intake is known.

Finally, there are of course genetic differences between these groups, the Indians from each other and both tribes from the Caucasoids. Whether these are relevant to the different responses observed cannot be determined from the data at hand. Given, however, the pressure for acculturation now overtaking even the most remote Amerindian tribes, the future medical history of these two Indian groups should provide important information for distinguishing genetic from 'life style' factors in the aetiology of non-insulin dependent diabetes mellitus.

Acknowledgements. This investigation was supported in part by US Public Health Service Grants AM-0888, AM-25556, GM-20138 and AM-02244, National Science Foundation Grant DEB-76-20591, and Department of Energy Contract EY-76-C-02-2828. We thank the Instituto Nacional das Pesquisas de Amazônia and the Fundação Nacional do Indio for the necessary clearances. We also thank the National Science Foundation for the base facilities provided by the $\mathrm{R} / V$ Alpha Helix.

\section{References}

1. Mayberry RH, Lindeman RD (1963) A survey of chronic disease and diet in Seminole Indians in Oklahoma. Am J Clin Nutr 13: $127-134$

2. Johnson JE, McNutt CW (1964) Diabetes mellitus in an American Indian Population isolate. Tex Rep Biol Med 22: 110-125

3. Miller M, Burch T, Bennett PH, Steinberg AG (1965) Prevalence of diabetes mellitus in the American Indians: results of glucose tolerance in the Cherokee Indians of North Carolina. Arch Int Med 116: 842-845

4. Stein JH, West KM, Robey JM, Tirador DF, McDonald GW (1965) The high prevalence of abnormal glucose tolerance in the Cherokee Indians of North Carolina. Arch Int Med 116:843-845

5. Saiki JH, Rimoin DL (1968) Diabetes mellitus among the Navajo. I Clinical features. Arch Int Med 122: 1-5

6. Henry RE, Burch TA, Bennett PH, Miller M (1969) Diabetes in the Cocopah Indians. Diabetes 18:33.37
7. Frohman LA, Doeblin TD, Emerling FG (1969) Diabetes in Seneca Indians: Plasma insulin responses to oral carbohydrates. Diabetes $18: 38-43$

8. Doeblin TD, Evans K, Ingall GB, Dowling K, Chilcote ME, Elsea W, Bannerman RM (1969) Diabetes and hyperglycemia in Seneca Indians. Hum Hered 19: 613-627

9. US Congress, Senate Committee on Government Operations, Subcommittee on Investigations (1974) Hearings on Indian Health Care. Ninety-Third Congress, Second Session. Government Printing Office, Washington

10. Sloan NR (1963) Ethnic distribution of diabetes mellitus in Hawaii. JAMA 183: 419-424

11. Bassett DR, Rosenblatt G, Moellering RC Jr, Hartwell AS (1966) Cardiovascular disease, diabetes mellitus, and anthropometric evaluation of Polynesian males on the Island of Niihau - 1963. Circulation 34: 1088-1097

12. Prior IAM, Rose BS, Harvey HPB, Davidson F (1966) Hyperuricaemia, gout and diabetic abnormality in Polynesian people. Lancet I: 333-338

13. Zimmet P, Whitehouse S (1978) Bimodality of fasting and twohour glucose tolerance distributions in a Micronesian population. Diabetes 27: 793-800

14. Rimoin DL, Merimee TJ, Rabinowitz D, Cavalli-Sforza LL, McKusick VA (1969) Peripheral subresponsiveness to human growth hormone in the African pygmies. New Eng J Med 281: 1383-1388

15. Merimee TJ, Rimoin DL, Cavalli-Sforza, LL (1972) Metabolic studies in the African pygmy. J Clin Invest 51: 395-401

16. Mohrenweiser H, Neel JV, Mestriner MA, Salzano FM, Migliazza E, Simoes AL, Yoshihara CM (1979) Electrophoretic variants in three Amerindian tribes: the Baniwa, Kanamari, and Central Pano of Western Brazil. Am J Phys Anthrop 50: 237-246

17. Chagnon NA (1974) Studying the Yanomamo. Holt, Rinehart and Winston, New York

18. Chagnon NA (1968) Yanomamo: The fierce people. Holt, Rinehart and Winston, New York

19. Neel JV (1978) The population structure of an Amerindian tribe, the Yanomama. Ann Rev Genet 12:365-413

20. Bondar RJL, Mead D (1974) Evaluation of glucose-6-phosphate dehydrogenase from Leuconostoc mesenteroides in the hexokinase method for determining glucose in serum. Clin Chem 20: $586-590$

21. Morgan CR, Lazarow A (1963) Immuṇoassay of insulin: two antibody system. Diabetes $12: 115-126$

22. Berger D, Crouther RC, Floyd JC Jr, Pek S, Fajans SS (1978) Effect of age on fasting plasma levels of pancreatic hormones in man. J Clin Endocrinol Metab 47: 1183-1189

23. Berger D, Floyd JC Jr, Lampman RM, Fajans SS (1980) The effect of adrenergic receptor blockade on the exercise-induced rise in pancreatic polypeptide in man. J Clin Endocrinol Metab 50: 33-39

24. Morrison DF (1976) Multivariate statistical methods, 2nd ed. McGraw-Hill, New York

25. Spielman RS, Da Rocha FJ, Weitkamp LR, Ward RH, Neel JV, Chagnon NA (1972) The genetic structure of a tribal population, the Yanomama Indians. VII. Anthropometric differences among Yanomama villages. Am J Phys Anthrop 37: 345-356

26. Rushforth NB, Bennett PH, Steinberg AG, Burch TA, Miller M (1971) Diabetes in the Pima Indians. Diabetes 20:756-765

27. Oliver WJ, Cohen EL, Neel JV (1975) Blood pressure, sodium intake, and sodium related hormones in the Yanomama Indians, a "no-salt" culture. Circulation 52: 146-151

Received: 31 December 1979

and in revised form: 14 April 1982

Dr. Richard S. Spielman

Department of Human Genetics-G3

University of Pennsylvania

School of Medicine

Philadelphia, PA 19104, USA 